\title{
Níveis de proteína bruta em dietas para bovinos de corte: consumo, digestibilidade e desempenho produtivo ${ }^{1}$
}

\author{
José Antônio Obeid2 ${ }^{2}$, Odilon Gomes Pereira ${ }^{2,3}$, Dalton Henrique Pereira ${ }^{4}$, Sebastião de \\ Campos Valadares Filho ${ }^{2,3}$, Isabela Pena Carvalho de Carvalho ${ }^{5}$, José Maria Martins ${ }^{6}$
}

\footnotetext{
1 Parte da tese de Doutorado apresentada à UFV.

2 Departamento de Zootecnia.

3 Bolsista CNPq.

${ }^{4}$ Doutorando em Zootecnia. Bolsista CNPq.

5 Graduanda em Zootecnia.

6 Técnico Agrícola, CEPET/UFV.
}

RESUMO - Foram avaliados o consumo e a digestibilidade total dos nutrientes, a taxa de passagem, o ganho de peso, o rendimento de carcaça e a conversão alimentar de bovinos de corte recebendo dietas com quatro níveis de PB (9, 11, 13 e 15\% na MS), formuladas com silagem de milho como volumoso e fornecidas na relação volumoso:concentrado de 60:40. Foram utilizados 24 novilhos zebuínos não-castrados (peso médio inicial de 381,6 kg), distribuídos em um delineamento em blocos casualizados, com quatro tratamentos e seis repetições. O período experimental foi de 84 dias, dividido em três períodos de 28 dias, após 15 dias de adaptação. A produção de fezes foi estimada utilizando-se a fibra em detergente ácido indigestível (FDAi), após incubação in situ por 144 horas. Os consumos de MS, MO, FDN, CNF e NDT e a taxa de passagem (Kp) estimada não foram influenciados pelos níveis crescentes de PB das dietas. Os consumos de PB e EE aumentaram linearmente com a elevação dos níveis de PB das dietas. As digestibilidades totais de MS, MO, EE e FDN não foram afetadas pelas dietas, mas a da PB aumentou linearmente com os níveis de PB das dietas. Os ganhos médios diários (GMD) e a conversão alimentar (CA) apresentaram resposta quadrática aos níveis crescentes de $\mathrm{PB}$, que, no entanto, não influenciaram o rendimento de carcaça (RC). Dietas com $12 \%$ de PB atendem às exigências de PB e PDR de novilhos zebuínos em fase de terminação com menores custos de produção.

Palavras-chave: carboidratos não-fibrosos, confinamento, fibra em detergente neutro, silagem de milho, soja grão, uréia

\section{Crude protein levels in beef cattle diets: intake, digestibility and performance}

\begin{abstract}
The objective of this trial was to investigate intake, apparent total tract digestibility of nutrients, passage rate, average daily gain, carcass yield, and feed conversion in beef cattle fed diets containing four levels of CP $(9,11,13$ and $15 \%$ ) and forage:concentrate ratio of 60:40. Twenty-four young Zebu bulls were assigned to a completely randomized block design with four treatments and six replications. The experiment lasted 84 days with 15 days for diet adaptation and three periods of 28 days for data and sample collection. Indigestible acid detergent fiber (IADF; ADF remaining after 144 hours of $i n$ situ incubation) was used to estimate fecal output. Intakes of DM, OM, NDF, NFC and TDN and estimated passage rate (Kp) all were not affected by the increasing levels of CP in the diet. Conversely, intakes of both CP and EE increased linearly when the dietary CP level varied from 9 to $15 \%$. No significant differences among treatments were observed for the apparent total tract digestibilities of DM, OM, EE, and NDF. However, digestibility of CP increased linearly with the incremental levels of CP in the diet. Significant quadratic effects were observed for the average daily body weight gain and feed conversion by increasing dietary CP but no diet effect was found for carcass yield. It can be concluded that diets with $12 \%$ of CP supplied the requirements of CP and RDP of finishing young Zebu bulls with the lowest production cost.
\end{abstract}

Key Words: corn silage, feedlot, non-fiber carbohydrate, neutral detergent fiber, urea, whole soybean

\section{Introdução}

Detentor do maior rebanho comercial bovino do mundo, o agronegócio brasileiro possui a pecuária de corte como uma das mais importantes atividades, representando uma parcela substancial do PIB e gerando mais de nove milhões de empregos diretos e indiretos. A partir da década de 90 , com as imposições da globalização, o setor pecuário (corte e leite) tem apresentado avanços expressivos de desenvolvimento, aumentando sua competitividade produtiva e 
econômica. Firmando-se como o maior exportador mundial de carne bovina a partir de 2003 (Cavalcanti, 2004), o Brasil, desde 2004, tende a se tornar também o maior exportador mundial de leite.

Com a maior área agricultável (apenas de cerrados o Brasil possui aproximadamente 151 milhões de hectares) e o maior reservatório de água doce do planeta, o Brasil tem condições de produzir pastagem e forragem conservada em alta escala e a baixo custo, permitind o o aumento do rebanho e da produção com qualidade. Os produtos de melhor qualidade e, portanto, de maior valor agregado, são demandados pelos países importadores, em especial aqueles de maior poder aquisitivo que, certamente remuneram melhor carne e leite livres de hormônios, probióticos e promotores de crescimento, comuns nos produtos americanos e europeus.

Como a maior parte do território brasileiro está localizada na região tropical, as forrageiras utilizadas estão sujeitas à estacionalidade de produção, resultando em grande deficiência quantitativa e qualitativa de forragem no período de estiagem. Com a tecnificação e a intensificação do processo produtivo na pecuária de corte, tem sido usada, entre outras, a prática do confinamento como alternativa na terminação de novilhos, pela qual alimentos volumosos conservados, principalmente silagens e fenos, constituem a principal fonte de nutrientes para a alimentação dos animais.

Por outro lado, a possibilidade de substituir parte da proteína verdadeira pelo nitrogênio não-protéico (NNP) como forma de reduzir o custo de produção tem levado ao aumento das pesquisas, em especial com a utilização da uréia. Os níveis de suplementação de dietas com uréia para a alimentação de bovinos em confinamento tem sido inconsistentes. A recomendação mais utilizada é a substituição de até $1 / 3$ do nitrogênio protéico da ração pela uréia, entretanto, Haddad (1984) sugere limitar a quantidade de uréia em, no máximo, 1,0\% da MS total da dieta. Salienta ainda que, quando os níveis de proteína na ração são elevados, principalmente se sua origem é NNP, pode ocorrer redução na palatabilidade e, conseqüentemente, no consumo, podendo ocasionar ainda, em caso de excesso de amônia no rúmen, altas perdas de nitrogênio urinário.

Magalhães et al. (2005), trabalhando com níveis crescentes de uréia $(0,00 ; 0,65 ; 1,30$ e $1,65 \%$ da MS total) para novilhos em confinamento, não encontraram diferenças nos ganhos de peso, que foram, respectivamente, de 1,21; 1,25; 1,28 e 1,08 kg/novilho/dia.

O consumo é um dos principais fatores que deteminaram o desempenho animal e, segundo Mertens (1994), 60 a $90 \%$ das variações de desempenho são atribuídas às oscilações no consumo, enquanto apenas 10 a 40\% são relacionadas à digestibilidade dos componentes nutritivos. Entre os fatores que mais influenciam o consumo, destaca-se o teor de proteína, que deve ser atendido pela absorção intestinal de aminoácidos provenientes principalmente da proteína microbiana sintetizada no rúmen e da proteína alimentar não degradada no rúmen (Valadares Filho \& Valadares, 2001).

A digestibilidade é um importante indicativo do valor nutritivo da dieta (Van Soest, 1994) e indica a porcentagem de cada nutriente utilizado pelo animal (Coelho da Silva \& Leão, 1979). Efeitos da concentração protéica da dieta sobre a digestibilidade têm sido mais consistentes quando utilizadas fontes protéicas degradadas no rúmen. Aumentos na digestibilidade aparente da MS com o aumento da PB na ração foram relatados por Valadares et al. (1997). Entretanto, Rennó et al. (2003), trabalhando com rações contendo 12 a $15 \%$ de $\mathrm{PB}$, verificaram efeito apenas sobre os coeficientes de digestibilidade aparente total de PB e EE.

Objetivou-se com este trabalho avaliar os consumos, as digestibilidades totais dos nutrientes, o desempenho produtivo e o rendimento de carcaça de novilhos zebus alimentados com dietas contendo diferentes níveis de PB.

\section{Material e Métodos}

O experimento foi conduzido na Central de Experimentação, Pesquisa e Extensão do Triângulo Mineiro (CEPET), da Universidade Federal de Viçosa. A CEPET localiza-se no município de Capinópolis - MG, com altitude média de $620,2 \mathrm{~m}$, latitude sul de $18^{\circ} 41^{\prime}$ e longitude oeste de $49^{\circ} 34^{\prime}$.

O clima é do tipo Aw, segundo a classificação de Köppen, quente e úmido, com temperatura do mês mais frio acima de $18^{\circ} \mathrm{C}$, com estação chuvosa no verão e seca no inverno e precipitação média anual de 1.400 a $1.600 \mathrm{~mm}$.

Foram utilizados 24 animais zebuínos, com peso médio inicial de $381,6 \mathrm{~kg}$, distribuídos em um delineamento em blocos casualizados, com quatro tratamentos e seis repetições.

Os tratamentos foram constituídos de rações à base de silagem de milho como volumoso, formuladas para conter 9, 11, 13 e 15\% de $\mathrm{PB}$ na MS, com relação volumoso:concentrado de 60:40. Os concentrados foram formulados à base de fubá de milho, minerais e uréia, adicionados de níveis crescentes de grãos de soja no momento da alimentação, à exceção da ração com $9 \%$ de PB, que não continha soja.

O milho (híbrido AG 1051), ensilado no estádio farináceoduro, foi proveniente de uma área de 3,0 ha, adubada com NPK (8-28-16) + Zn (300 kg/ha) e 100 kg de uréia em cobertura. 
Os custos (US $\$ / 100 \mathrm{~kg}$ ) e a proporção dos ingredientes nos concentrados, expressa com base na matéria natural, bem como os custos (US\$/animal/dia) e a proporção dos ingredientes nas dietas experimentais, expressa com base na MS, encontram-se nas Tabelas 1 e 2, respectivamente.

A composição químico-bromatológica dos concentrados, da silagem e das rações experimentais encontra-se nas Tabelas 3 e 4 , respectivamente.

O período experimental foi de 84 dias, divididos em três períodos de 28 dias, após 15 dias de adaptação.

Após pesagem e everminação, os animais foram alojados em baias individuais $\left(10 \mathrm{~m}^{2}\right)$ contendo comedouro coberto e bebedouro, onde receberam a alimentação, duas vezes ao dia (7 e $15 \mathrm{~h})$, em quantidade suficiente para ocorrer $10 \%$ de sobras.

Durante o período experimental, diariamente, avaliou-se o consumo e coletaram-se amostras dos alimentos fornecidos e das sobras de cada animal, que foram acondicionadas em sacos plásticos, identificadas e armazenadas em freezer.

As pesagens inicial e final foram realizadas com os animais em jejum completo de 14 horas e as intermediárias, com os animais sem jejum.

Para o ensaio de digestibilidade e estimativa da produção fecal utilizando-se a FDAi como indicador, as fezes foram coletadas diretamente no piso, uma vez ao dia antes da primeira alimentação, entre o 430 e 480 o dia experimental. Nesta ocasião, foram também coletadas amostras dos alimentos fornecidos e das sobras.

Todas as amostras foram submetidas à pré-secagem em estufa com ventilação forçada (a $65^{\circ} \mathrm{C}$, por 72 horas) e, posteriormente, foram trituradas em moinho de facas, tipo Willey, com peneira de 30 mesh, sendo armazenadas em frascos de vidro com tampa de polietileno para posteriores análises.

Tabela 1 - Proporção dos ingredientes nos concentrados, com base da matéria natural, e custo do concentrado para as diferentes rações Table 1 - Ingredient composition (as-fed basis) and cost of the concentrates

\begin{tabular}{|c|c|c|c|c|}
\hline \multirow[t]{2}{*}{$\begin{array}{l}\text { Ingrediente } \\
\text { Ingredient }\end{array}$} & \multicolumn{4}{|c|}{$\begin{array}{c}\text { Nível de PB (\%) } \\
\text { CP level (\%) }\end{array}$} \\
\hline & 9 & 11 & 13 & 15 \\
\hline Grão de soja inteiro (Whole soybean) & 0,00 & 11,02 & 22,02 & 33,12 \\
\hline Uréia/SA ${ }^{1}($ Urea/AS) & 1,64 & 2,28 & 2,93 & 3,59 \\
\hline Calcário (Limestone) & 0,36 & 0,36 & 0,36 & 0,36 \\
\hline Premix mineral $^{2}$ (Mineral mix) & 0,03 & 0,03 & 0,03 & 0,03 \\
\hline $\mathrm{Custo}^{3}(\mathrm{U} \$ S / 100 \mathrm{~kg})^{4}($ Cost, $U \$ S / 100 \mathrm{~kg})$ & 13,14 & 14,04 & 14,95 & 15,86 \\
\hline
\end{tabular}

Tabela 2 - Proporção dos ingredientes nas dietas experimentais, com base na MS, e custo total das rações

Table 2 - Ingredient composition (\% of DM) and total cost of the experimental diets

\begin{tabular}{|c|c|c|c|c|}
\hline \multirow[t]{2}{*}{$\begin{array}{l}\text { Ingrediente } \\
\text { Ingredient }\end{array}$} & \multicolumn{4}{|c|}{$\begin{array}{c}\text { Nível de PB (\%) } \\
\text { CP level }(\%)\end{array}$} \\
\hline & 9 & 11 & 13 & 15 \\
\hline Milho grão moído (Ground corn) & 38,48 & 33,77 & 29,06 & 24,34 \\
\hline Grão de soja inteiro ${ }^{1}$ (Whole soybean) & 0,00 & 4,44 & 8,86 & 13,29 \\
\hline Uréia/AS(Urea/AS) & 0,73 & 1,00 & 1,29 & 1,58 \\
\hline Fosfato bicálcico (Dicalcium phosphate) & 0,32 & 0,32 & 0,32 & 0,32 \\
\hline Premix mineral (Mineral mix) & 0,015 & 0,015 & 0,015 & 0,015 \\
\hline Custo $^{1}$ (U\$S/animal/dia) $)^{2}$ Cost, U\$S/animal/day) & 0,99 & 1,12 & 1,12 & 1,19 \\
\hline
\end{tabular}

1 Calculado considerando a quantidade total de MS fornecida por animal/dia (Calculated considering the total amount of DM fed daily to each animal). Custo da silagem de milho (Cost of corn silage): $\mathrm{R} \$ 0,19 / \mathrm{kg}$ MS (R\$ 0.19/kg DM). (Anualpec, 2005; corrigido para 35,19\% de MS) (Anualpec, 2005; corrected for 35.19\% of DM).

2 Dólar $=\mathrm{R} \$ 2,34$ (Dollar $=R \$ 2.34$ ). 
Tabela 3 - Composição química (teores médios) do grão de soja, da silagem de milho e dos concentrados utilizados nas rações Table 3 - Chemical composition of whole soybean, corn silage and concentrates used in the diets

\begin{tabular}{|c|c|c|c|c|c|c|}
\hline \multirow{3}{*}{$\begin{array}{l}\text { Item } \\
\text { Item }\end{array}$} & \multirow{3}{*}{$\begin{array}{l}\text { Grão de soja } \\
\text { Whole soybean }\end{array}$} & \multirow{3}{*}{$\begin{array}{l}\text { Silagem de milho } \\
\text { Corn silage }\end{array}$} & \multirow{2}{*}{\multicolumn{4}{|c|}{$\begin{array}{c}\text { Concentrado }^{2}(\%) \\
\text { Concentrate }(\%) \\
\end{array}$}} \\
\hline & & & & & & \\
\hline & & & 9 & 11 & 13 & 15 \\
\hline $\operatorname{MS}(\%)(D M \%)$ & 89,19 & 35,19 & 87,40 & 88,37 & 87,91 & 87,80 \\
\hline $\mathrm{MO}(\%)(O M \%)$ & 94,68 & 96,87 & 96,91 & 96,76 & 97,04 & 96,50 \\
\hline PB (\%) (CP \%) & 36,56 & 7,33 & 13,19 & 16,57 & 19,68 & 20,92 \\
\hline $\operatorname{NIDN}(\%)^{1}(N D I N \%)$ & 5,94 & 22,11 & 4,68 & 2,35 & 3,36 & 3,24 \\
\hline NIDA $(\%)^{1}(A D I N \%)$ & 4,58 & 5,28 & 1,30 & 1,27 & 1,23 & 1,15 \\
\hline $\mathrm{EE}(\%)(E E \%)$ & 13,88 & 3,02 & 2,37 & 2,62 & 2,10 & 2,42 \\
\hline FDN $(\%)(N D F \%)$ & 13,85 & 46,95 & 12,42 & 10,64 & 10,24 & 10,67 \\
\hline $\operatorname{FDNcp}(\%)\left(N D F_{a p} \%\right)^{2}$ & 13,37 & 45,93 & 11,74 & 9,80 & 9,33 & 9,83 \\
\hline $\mathrm{CNF}(\%)(N F C \%)$ & 30,39 & 39,57 & 72,89 & 72,31 & 71,76 & 70,44 \\
\hline FDA $(\%)(A D F \%)$ & 7,14 & 21,13 & 2,50 & 2,40 & 2,35 & 2,24 \\
\hline Lignina (\%)(Lignin \%) & 2,13 & 6,56 & 1,81 & 1,73 & 1,63 & 1,81 \\
\hline $\operatorname{NDT}(\%)(T D N \%)$ & 93,82 & 64,28 & 85,93 & 88,18 & 89,43 & 90,19 \\
\hline
\end{tabular}

${ }^{1}$ Porcentagem na PB (\% CP); ${ }^{2}$ Concentrados constituídos de milho em grão moído, uréia/SA e mistura mineral (Concentrates composed by ground corn grain, 9:1 urea/ AS and mineral mixtures).

${ }^{2}$ FDN corrigida para cinzas e proteína (neutral detergent fiber corrected for ash and protein).

Tabela 4 - Composição química (teores médios) das rações experimentais

Table 4 - Chemical composition of the four experimental diets

\begin{tabular}{|c|c|c|c|c|}
\hline \multirow[t]{2}{*}{$\begin{array}{l}\text { Item } \\
\text { Item }\end{array}$} & \multicolumn{4}{|c|}{$\begin{array}{c}\text { Nível de PB (\%) } \\
\text { CP level }(\%)\end{array}$} \\
\hline & 9 & 11 & 13 & 15 \\
\hline $\operatorname{MS}(\%)(D M \%)$ & 56,07 & 56,50 & 56,39 & 56,42 \\
\hline $\mathrm{MO}(\%)(O M \%)$ & 96,89 & 96,73 & 96,73 & 96,48 \\
\hline $\mathrm{PB}(\%)(C P \%)$ & 9,67 & 11,91 & 13,76 & 14,84 \\
\hline $\operatorname{EE}(\%)(E E \%)$ & 2,76 & 3,36 & 3,70 & 4,30 \\
\hline $\operatorname{FDN}(\%)(N D F \%)$ & 33,14 & 32,57 & 32,59 & 32,86 \\
\hline $\operatorname{FDNcp}(\%)\left(N D F_{a p} \%\right)^{l}$ & 32,25 & 31,65 & 31,67 & 31,99 \\
\hline $\operatorname{CNF}(\%)(N F C \%)$ & 52,90 & 50,80 & 48,78 & 46,60 \\
\hline $\operatorname{FDA}^{1}(\%)(A D F \%)$ & 13,68 & 13,85 & 14,04 & 14,23 \\
\hline Lignina (\%) (Lignin \%) & 4,66 & 4,65 & 4,63 & 4,70 \\
\hline $\operatorname{NDT}(\%)(T D N \%)$ & 72,94 & 74,09 & 74,73 & 75,13 \\
\hline
\end{tabular}

${ }^{1}$ FDN corrigida para cinzas e proteína (NDF corrected for ash and protein).

As análises dos teores de MS, MO, EE, compostos nitrogenados $(\mathrm{N})$, lignina, nitrogênio insolúvel em detergente ácido (NIDA) e nitrogênio insolúvel em detergente neutro (NIDN) foram feitas segundo procedimentos descritos por Silva \& Queiroz (2002).

A composição em FDN e FDA foi determinada pela técnica da autoclave, segundo Pell \& Schofield (1993). A correção da FDN para cinzas e proteína (FDNcp) foi realizada nas amostras de alimentos para cálculo da digestibilidade da FDN e do NDT das rações.

Os teores de NDT foram obtidos a partir da equação: $N D T=P B D+2,25 E E D+F D N c p D+C N F D$ em que PBD, EED, FDNcp e CNFD significam, respectivamente, PB digestível, EE digestível, FDN digestível corrigida para cinza e proteína e CNF digestíveis. Os carboidratos nãofibrosos (CNF) foram calculados como proposto por Hall
(2000): $C N F=100-[(\%$ PB $-\%$ PB derivada da uréia $+\%$ de uréia $)+\% F D N+\% E E+\%$ cinzas $]$.

As concentrações de FDAi foram determinadas nas amostras de alimentos, sobras e fezes, por meio de incubação ruminal por 144 horas de $0,5 \mathrm{~g}$ de amostra em sacos de Ankom (filter bags F57), que, posteriormente, foram lavados em água corrente, fervidos em detergente ácido por uma hora, lavados em água destilada fervente por 10 minutos e, em seguida, com acetona (por duas vezes), sendo secos em estufa a $65^{\circ} \mathrm{C}$ por 72 horas, para determinação da FDAi.

A taxa de passagem foi estimada por meio das equações preditas pelo NRC (2001) para forrageiras úmidas $\left(K p=3,054+0,614 X_{1}\right)$ e para alimentos concentrados $\left(K p=2,904+1,375 X_{1}-0,020 X_{2}\right)$, em que $\mathrm{X}_{1}$ equivale ao consumo de matéria seca em relação ao peso corporal e $X_{2}$, à porcentagem de $\mathrm{PB}$ na ração.

Os teores de proteína degradável no rúmen (PDR) foram calculados conforme recomendações do NRC (2001), por meio da equação: $P D R=A+B *(k d / k d+k p)$, em que $\mathrm{A}, \mathrm{B}$, kd e kp significam, respectivamente, fração solúvel em água, fração insolúvel em água e potencialmente degradável, taxa de degradação da fração $\mathrm{B}$ e taxa de passagem da $\mathrm{PB}$ pelo rúmen. Os valores de A (\%), B (\%) e kd (\%/hora) adotados foram: 54,72; 36,0 e 6,68 para silagem de milho; 21,$93 ; 74,21$ e 4,03 para fubá de milho e 29,10; 70,90 e 9,90 para grãos de soja, respectivamente (Valadares Filho et al., 2002). Os valores de kp estimados foram de $4,63 \%$ /hora para silagem de milho e 5,73\%/hora para fubá de milho e grão de soja, sendo utilizado o valor médio de 5\%/hora para todos os ingredientes das dietas.

Após o abate dos animais, foram avaliados os rendimentos de carcaça (RC), expressos pela divisão do peso de 
carcaça quente (PCQ) pelo respectivo peso corporal final (PVF) de cada animal, submetido a jejum de 14 horas.

As variáveis estudadas foram submetidas às análises de variância e regressão utilizando-se o Sistema de Análises Estatísticas e Genéticas - SAEG (UFV, 2001). Os modelos foram escolhidos utilizando-se como critérios a significância entre as dietas, por meio do teste $\mathrm{F}$ a $5 \%$ de probabilidade, e por meio dos coeficientes de determinação.

\section{Resultados e Discussão}

A silagem de milho utilizada apresentou valor médio de $\mathrm{pH}$ de 3,8 , concentração de $\mathrm{N}-\mathrm{NH}_{3}$, em porcentagem do nitrogênio total, de 5,94\%, e baixo teor de FDN (46,95\%), o que permite classificá-la como de ótima qualidade (McDonald et al., 1991).

As médias, as equações de regressão e os respectivos coeficientes de determinação $\left(\mathrm{r}^{2}\right)$ e de variação $(\mathrm{CV}, \%)$ para os consumos diários de componentes nutritivos, em função dos níveis de $\mathrm{PB}$, encontram-se na Tabela 5.

Os consumos diários de MS (kg/dia e \%PV) e MO $(\mathrm{kg} / \mathrm{dia})$ não foram influenciados $(\mathrm{P}>0,05)$ pelos níveis de PB das rações e apresentaram valores médios de $9,18 \mathrm{~kg} / \mathrm{dia}$ e $2,1 \%$ do PV (consumos de MS) e de $8,89 \mathrm{~kg} / \mathrm{dia}$ (consumo de MO). Certamente, a quantidade de compostos nitrogenados nas diferentes rações experimentais atendeu às exigências dos microrganismos ruminais, não influenciando, portanto, o consumo destes componentes nutritivos. Segundo Van Soest (1994), concentrações de PB superiores a 7\% na MS total não influenciam a ingestão de MS pelos bovinos. Valadares et al. (1997) tambémobservaram redução de consumo apenas quando a ração continha $7 \%$ de PB e encontra ram consumos de MS mais elevados e iguais entre si para as rações contendo 9,5; 12,0 e 14,5\% de PB. Trabalhos de Magalhães et al. (2005) e Cavalcante et al. (2005) utilizando uma única relação volumoso:concentrado e níveis crescentes de PB, não revelaram aumento no consumo quando os níveis de PB foram superiores a 7\%. Independentemente da forma de expressão, Carvalho et al. (1997), Cardoso et al. (2000), Ítavo et al. (2002a) e Moraes et al. (2002) também não verificaram variação no consumo com o aumento do concentrado quando as dietas possuíam níveis superiores a 7\% de PB. Diferentemente, Dias et al. (2000) e Silva et al. (2003) obtiveram aumento linear no consumo de MS e MO quando aumentaram a quantidade de concentrado nas dietas experimentais.

Como esperado, o consumo de PB ( $\mathrm{kg} / \mathrm{dia})$ aumentou linearmente $(\mathrm{P}<0,05)$ com a elevação dos teores de $\mathrm{PB}$ nas rações, o que está consoante com os resultados obtidos por
Ítavo et al. (2002b). Considerando que a exigência para bovinos de corte com peso de $450 \mathrm{~kg}$ e ganho de $1,0 \mathrm{~kg} / \mathrm{dia}$ é de 0,921 kg de PB (NRC, 1996), pode-se afirmar que as demais rações atenderam aos requerimentos de $\mathrm{PB}$ dos animais, à exceção daquela com $9 \%$ de PB, que atendeu $96 \%$ da exigência deste nutriente.

$\mathrm{O}$ consumo de EE aumentou linearmente $(\mathrm{P}<0,05)$ com a elevação dos níveis de $\mathrm{PB}$ nas rações, certamente em decorrência dos níveis crescentes de grãos de soja, visto que o consumo de MS não variou entre as dietas.

O consumo de FDN, independentemente de sua forma de expressão ( $\mathrm{kg} /$ dia ou \% PV), não foi influenciado ( $\mathrm{P}>0,05)$ pelas rações, o que era esperado tendo-se em vista a similaridade no consumo de MS e nos teores de FDN nas rações. Considerando a recomendação do NRC (1996) de $6,33 \mathrm{~kg} / \mathrm{dia}$ de NDT para animais com $450 \mathrm{~kg}$ e ganho diário de $1,0 \mathrm{~kg}$, à exceção da ração com 9\% de PB (sem soja), as demais atenderam às exigências em NDT dos animais.

$\mathrm{Na}$ Tabela 6 são relacionados os coeficientes de digestibilidade total dos componentes nutritivos, as equações de regressão ajustadas em função dos níveis de PB das dietas e os respectivos coeficientes de determinação $\left(\mathrm{r}^{2}\right) \mathrm{e}$ de variação (CV \%).

As digestibilidades totais de MS, MO, EE e FDN não foram influenciadas $(\mathrm{P}>0,05)$ pelos níveis de $\mathrm{PB}$ das rações, apresentando médias de 70,61;71,60; 72,06 e 43,65, respectivamente. Esses resultados eram esperados, pois não houve elevação do consumo de CNF com o aumento dos níveis de $\mathrm{PB}$ nas dietas. Entretanto, resultados de literatura nos quais foram utilizados diferentes níveis de concentrado revelaram aumentos lineares nos coeficientes de digestibilidade da MS e MO com a elevação dos níveis de PB nas dietas (Ítavo et al., 2002a) ou mesmo efeitos quadráticos (Ladeira et al., 1999).

Os coeficientes de digestibilidade aparente total da PB aumentaram linearmente $(\mathrm{P}<0,05)$ com o aumento dos níveis de $\mathrm{PB}$, o que está de acordo com os resultados descritos por Cardoso et al. (2000) e Dias et al. (2000). Entretanto, Ítavo et al. (2002a) e Moraes et al. (2002) não encontraram efeito de níveis de concentrado sobre os coeficientes de digestibilidade aparente total da PB.

A taxa de passagem (Kp) estimada $(0,0460 \pm 0,0012 /$ hora) não foi influenciada $(\mathrm{P}>0,05)$ pelos níveis de $\mathrm{PB}$ nas rações, sendo semelhante à obtida por Pereira (2004).

Na Tabela 7, constam os pesos corporais inicial (PVI) e final (PVF), o ganho de peso médio diário (GMD), o rendimento de carcaça (RC), a conversão alimentar (CA), o custo da arroba produzida considerando o alimento (US\$/@), as equações de regressão e os coeficientes de determinação $\left(\mathrm{r}^{2}\right)$ e variação (CV\%) obtidos nos tratamentos. 
Tabela 5 - Consumos médios diários de nutrientes e respectivas equações de regressão e coeficientes de determinação $\left(r^{2}\right)$ e de variação $(\mathrm{CV})$, em função dos níveis de $\mathrm{PB}$ das rações

Table 5 - Average daily intakes of DM, OM, CP,EE, NDF, NFC, TDN and respective regression equations, and coefficients of determination $\left(r^{2}\right)$ and variation (CV) according to increasing levels of $C P$ in the diet

\begin{tabular}{|c|c|c|c|c|c|c|c|}
\hline \multirow[t]{2}{*}{$\begin{array}{l}\text { Item } \\
\text { Item }\end{array}$} & \multicolumn{4}{|c|}{$\begin{array}{c}\text { Nível de PB }(\%) \\
\text { CP level }(\%)\end{array}$} & \multirow[t]{2}{*}{$\begin{array}{l}\text { Equação } \\
\text { Equation }\end{array}$} & \multirow[t]{2}{*}{$\mathrm{r}^{2}$} & \multirow[t]{2}{*}{$\mathrm{CV}(\%)$} \\
\hline & 9 & 11 & 13 & 15 & & & \\
\hline & \multicolumn{4}{|c|}{$\begin{array}{l}\text { Consumo }(\mathrm{kg} / \mathrm{dia}) \\
\text { Intake }(\mathrm{kg} / \text { day })\end{array}$} & & & \\
\hline $\operatorname{MS}(D M)$ & 8,70 & 9,52 & 9,16 & 9,49 & $\hat{\mathrm{y}}=9,18$ & - & 8,36 \\
\hline $\mathrm{MO}(O M)$ & 8,44 & 9,21 & 8,87 & 9,17 & $\hat{y}=8,89$ & - & 8,35 \\
\hline $\mathrm{PB}(C P)$ & 0,88 & 1,12 & 1,28 & 1,50 & $\hat{\mathrm{y}}=-0,588984+0,104071 * * \mathrm{~PB}$ & 0,99 & 8,63 \\
\hline $\mathrm{EE}(E E)$ & 0,28 & 0,35 & 0,35 & 0,44 & $\hat{\mathrm{y}}=0,080633+0,0229285^{*} * \mathrm{~PB}$ & 0,89 & 9,37 \\
\hline $\mathrm{FDN}(N D F)$ & 2,72 & 2,90 & 2,89 & 2,97 & $\hat{\mathrm{y}}=2,86$ & - & 7,82 \\
\hline $\mathrm{CNF}(N F C)$ & 4,65 & 4,89 & 4,45 & 4,42 & $\hat{\mathrm{y}}=4,60$ & - & 9,48 \\
\hline \multirow[t]{2}{*}{$\operatorname{NDT}(T D N)$} & 6,02 & 6,95 & 6,57 & 6,88 & $\hat{\mathrm{y}}=6,60$ & - & 8,33 \\
\hline & \multicolumn{4}{|c|}{$\begin{array}{c}\text { Consumo }(\% \mathrm{PV}) \\
\text { Intake }(\% B W)\end{array}$} & & & \\
\hline $\mathrm{MS}(D M)$ & 2,07 & 2,14 & 2,06 & 2,12 & $\hat{\mathrm{y}}=2,10$ & - & 7,91 \\
\hline $\mathrm{FDN}(N D F)$ & 0,65 & 0,65 & 0,65 & 0,66 & $\hat{\mathrm{y}}=0,65$ & - & 7,48 \\
\hline
\end{tabular}

* $(\mathrm{P}<0,05) ;{ }^{* *}(\mathrm{P}<0,01)$.

Tabela 6 - Médias das digestibilidades totais de MS, MO, PB, EE e FDN, respectivas equações de regressão e coeficientes de determinação $\left(r^{2}\right)$ e de variação, em função dos níveis de $\mathrm{PB}$ nas rações

Table 6 - Means of apparent total tract digestibilities of DM, OM, CP, EE, FDN and respective regression equations, and coefficients of determination ( ${ }^{2}$ ) and variation (CV) according to increasing levels of $\mathrm{CP}$ in the diet

\begin{tabular}{|c|c|c|c|c|c|c|c|}
\hline \multirow[t]{2}{*}{$\begin{array}{l}\text { Item } \\
\text { Item }\end{array}$} & \multicolumn{4}{|c|}{$\begin{array}{c}\text { Nível de PB (\%) } \\
\text { CP level }(\%)\end{array}$} & \multirow[t]{2}{*}{$\begin{array}{l}\text { Equação } \\
\text { Equation }\end{array}$} & \multirow[t]{2}{*}{$\mathrm{r}^{2}$} & \multirow[t]{2}{*}{$\mathrm{CV}(\%)$} \\
\hline & 9 & 11 & 13 & 15 & & & \\
\hline $\operatorname{MS}(D M)$ & 69,55 & 72,23 & 70,22 & 70,43 & $\hat{y}=70,61$ & - & 4,12 \\
\hline $\mathrm{MO}(O M)$ & 70,59 & 73,11 & 71,10 & 71,60 & $\hat{y}=71,60$ & - & 4,11 \\
\hline $\mathrm{PB}(C P)$ & 63,85 & 73,37 & 72,69 & 73,64 & $\hat{\mathrm{y}}=53,6782+1,43421 * * \mathrm{~PB}$ & 0,62 & 4,81 \\
\hline $\mathrm{EE}(E E)$ & 67,71 & 75,05 & 72,04 & 73,43 & $\hat{y}=72,06$ & - & 6,51 \\
\hline $\mathrm{FDN}(N D F)$ & 42,53 & 44,86 & 43,50 & 43,73 & $\hat{y}=43,65$ & - & 11,06 \\
\hline
\end{tabular}

** $(\mathrm{P}<0,01)$.

O GMD apresentou resposta quadrática $(\mathrm{P}<0,05)$ ao aumento dos níveis de $\mathrm{PB}$ nas rações (Tabela 7), estimando-se valor máximo de $1,47 \mathrm{~kg} /$ dia para o nível de $13 \%$ de $\mathrm{PB}$ na ração. Comportamento quadrático foi relatado também por Hoffman et al. (2001), ao testarem níveis de PB de 8, 11, 13 e $15 \%$. Cavalcante et al. (2005), no entanto, não verificaram efeito dos níveis de PB na dieta sobre o GMD de novilhos nelorados, cujo ganho médio foi de $1,074 \mathrm{~kg} / \mathrm{dia}$. Constata-se que a utilização de nível de uréia superior em até $58 \%$ ao recomendado por Haddad (1984) não prejudicou o GMD dos animais.
Como demonstrado na Figura 1, a quantidade ideal de $\mathrm{PB}$ para os animais utilizados neste ensaio foi de $1,11 \mathrm{~kg} / \mathrm{dia}$ para ganho de peso médio diário de 1,43 kg/animal. Esses animais apresentaram consumo médio de MS de 19,18 kg/animal/dia (média de $12 \%$ de PB na MS total), sugerindo que esse teor de $\mathrm{PB}$ foi equivalente às exigências dos animais nesta pesquisa.

O GMD de 1,43 kg/dia foi obtido com consumo ótimo de PDR de 0,684 kg/dia (Figura 2), o que equivale a 7,5\% de PDR na MS ingerida ou a 61,6\% de PDR na PB total requerida. Contudo, consumos de PDR superiores a 
$1,111 \mathrm{~kg} /$ dia resultaram em mesmo ganho diário, o que permite inferir que as exigências de $\mathrm{PB}$ podem ser supridas exclusivamente pela PDR da dieta.

Assim, pode-se afirmar que as exigências de novilhos de corte zebuínos em confinamento com peso médio inicial de $382 \mathrm{~kg}$ foram de $12 \%$ de PB e de 7,5\% de PDR na MS total.

$\mathrm{O}$ teor de $\mathrm{PB}$ das dietas não influenciou $(\mathrm{P}>0,05)$ o RC, o que estáde acordo com os resultados obtidos por Ferreira et al. (1999), Souza et al. (2002) e Cavalcante et al. (2005).

A conversão alimentar ajustou-se a um modelo quadrático $(\mathrm{P}<0,05)$, estimando-se ponto de mínimo de 6,34 para o nível de 13,6\% de $\mathrm{PB}$ nas rações, próximo àquele que resultou em GMD máximo, o que está de acordo com os resultados descritos por Ferreira et al. (1999). A maior participação de grãos de soja nas rações resultou em maior ingestão $(\mathrm{P}<0,05)$ de $\mathrm{PB}, \mathrm{EE}$ e NDT, requerendo menor quantidade de alimento para o ganho de peso.

Considerando o GMD e o custo das rações consumidas, os custos por $\mathrm{kg}$ de peso produzido durante o experimento foram de US $\$ 0,85 ; 0,78 ; 0,78$ e 0,82 para os níveis de PB de 9 , $11,13 \mathrm{e} 15 \%$, respectivamente. O custo por $\mathrm{kg}$ de peso foi igual para os tratamentos com 11 e $13 \%$ de PB e superior em 9 e $5 \%$ para os tratamentos com 9 e $15 \%$ de $\mathrm{PB}$, respectivamente.

Tomando como base os valores de mercado e os dados deste trabalho, algumas alternativas podem ser analisadas pelo pecuarista. Primeira: considerando-se R \$ 53,00

Tabela 7 - Médias dos pesos vivos inicial (PVI) e final (PVF), ganhos médios diários de peso vivo (GMD), rendimento de carcaça (RC), conversão alimentar (CA), custo da arroba considerando o alimento (US\$/@), respectivas equações de regressão e coeficientes de determinação $\left(r^{2}\right)$ e de variação $(C V)$ em função dos níveis de PB nas rações

Table 7 - Means for the initial (IBW) and final (FBW) body weights, daily body weight gains (DBWG), carcass yield (CY), feed conversion (FC), cost per $@$ for each feed (U\$S/@) and respective regression equations, and coefficients of determination $\left(r^{2}\right)$ and variation (CV) according to increasing levels of $\mathrm{CP}$ in the diet

\begin{tabular}{|c|c|c|c|c|c|c|c|}
\hline \multirow[t]{2}{*}{$\begin{array}{l}\text { Item } \\
\text { Item }\end{array}$} & \multicolumn{4}{|c|}{$\begin{array}{c}\text { Nível de PB (\%) } \\
\text { CP level }(\%)\end{array}$} & \multirow[t]{2}{*}{$\begin{array}{l}\text { Equação } \\
\text { Equation }\end{array}$} & \multirow[t]{2}{*}{$\mathrm{r}^{2} / \mathrm{R}^{2}$} & \multirow[t]{2}{*}{$\mathrm{CV}(\%)$} \\
\hline & 9 & 11 & 13 & 15 & & & \\
\hline $\mathrm{PVI}^{1}(I B W)$ & 371,83 & 385,67 & 384,33 & 385,17 & $\hat{y}=381,75$ & - & 2,95 \\
\hline $\operatorname{PVF}^{1}(F B W)$ & 468,67 & 505,00 & 503,00 & 508,50 & $\hat{y}=496,29$ & - & 2,82 \\
\hline $\operatorname{GMD}^{2}(D B W G)$ & 1,17 & 1,44 & 1,43 & 1,41 & $\hat{\mathrm{y}}=-1,5859+0,46992 * \mathrm{~PB}-0,018065 * \mathrm{~PB}^{2}$ & 0,93 & 11,18 \\
\hline $\mathrm{RC}^{3}(C Y)$ & 52,58 & 50,78 & 51,22 & 51,72 & $\hat{\mathrm{y}}=51,50$ & - & 3,95 \\
\hline $\mathrm{CA}^{4}(F C)$ & 7,52 & 6,68 & 6,42 & 6,44 & $\hat{\mathrm{y}}=16,4563-1,48735 * \mathrm{~PB}+0,0546976 * \mathrm{~PB}^{2}$ & 0,99 & 8,15 \\
\hline Custo $^{5}$ (Cost) & 24,54 & 23,40 & 23,26 & 24,88 & - & - & - \\
\hline
\end{tabular}

${ }^{*}(\mathrm{P}<0,05) ;{ }^{1}(\mathrm{~kg}) ;{ }^{2}(\mathrm{~kg} / \mathrm{dia})(\mathrm{kg} /$ day $) ;{ }^{3}(\%) ;{ }^{4}(\mathrm{~kg} \mathrm{MS} / \mathrm{kg} \mathrm{GPV})\left(\mathrm{kg}\right.$ DM/kg LBG); ${ }^{5}$ Custo da @ composto apenas do custo do alimento, calculado em US $\$ / @$ produzida durante o experimento, considerando o rendimento de carcaça (Cost per @ including only the cost of each feed, calculated in US\$/@ yielded during the experiment, considering carcass yield).

Dólar $=\mathrm{R} \$ 2,34$.

Dollar $=R \$ 2.34$

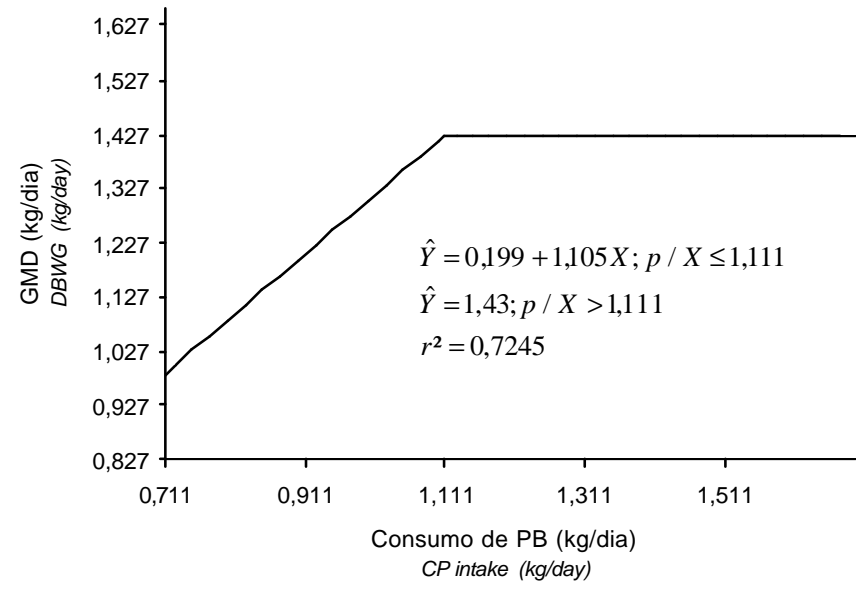

Figura 1 - Ganho médio diário (kg/dia) em função do consumo de PB (kg/dia).

Figure 1 - Daily body weight gain (DBWG) as function of CP intake ( $\mathrm{kg} /$ day).

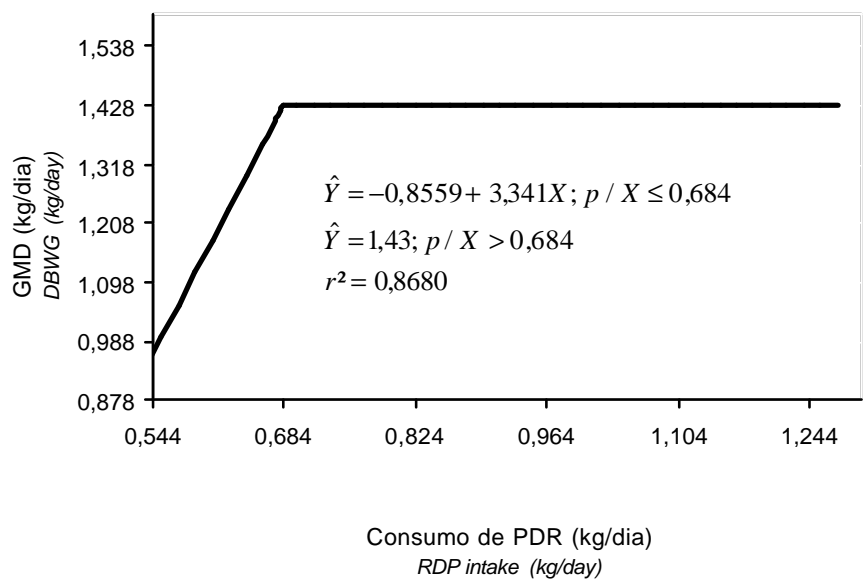

Figura 2 - Ganho médio diário (kg/dia) em função do consumo proteína degradável no rúmen ( $\mathrm{kg} / \mathrm{dia})$.

Figure 2 - Daily body weight daily gain (DBWG) as function of rumendegradable protein intake $(\mathrm{kg} / \mathrm{day})$. 
(US\$ 23,92) o atual preço da arroba, a melhor dieta experimental (13\% PB) propiciou lucro de US\$ 0.20/@ produzida. Como a duração do confinamento foi de 84 dias e o GMD de $1,47 \mathrm{~kg}$, obteve-se produção de 4,22 @ (carcaça) e um lucro de US\$ 0.85/animal confinado. Segunda: considerando a possibilidade de aluguel da pastagem (US\$ 5.13/animal/mês - Anualpec 2005) desocupada pelo animal confinado, é possível obter receita de US\$15.166 durante o período de confinamento. Além disso, o acabamento precoce dos animais, propiciado pelo confinamento, resulta em giro mais rápido do capital empatado e proporciona a reposição de animais a pasto em pleno período de estiagem, quando seu estado corporal favorece o comprador.

Como terceira alternativa, se os animais permanecessem em pastagem sem suplementação, cada animal perderia estimadamente $30 \mathrm{~kg}$ de PV durante o período de estiagem (0,25 kg/novilho dia durante 120 dias - julho a outubro). Ganhando cerca de $0,6 \mathrm{~kg} / \mathrm{animal} /$ dia no período das águas (novembro a maio), os animais só atingiriam o peso obtido no confinamento (503 kg) em 18/05 do ano subseqüente, mesmo assim, considerando a adição dos $30 \mathrm{~kg}$ perdidos na seca como ganho compensatório. Nesta hipótese, o confinamento proporcionaria a possibilidade de aluguel da pastagem por um período de 10,6 meses (julho a 18 de maio), com receita unitária de US\$ 58,20, resultando em um lucro de US\$ 46.40/animal confinado, deduzido o prejuízo de US\$ 7.98 ocasionado pelo custo do alimento utilizado no confinamento.

\section{Conclusões}

As exigências de bovinos zebuínos em confinamento com $382 \mathrm{~kg}$ de PV inicial e $496 \mathrm{~kg}$ de PV final foram de aproximadamente $1,11 \mathrm{~kg}$ de $\mathrm{PB} / \mathrm{dia}$, equivalente, neste experimento, a $12 \%$ de PB na MS. A ingestão mínima de PDR foi de $0,684 \mathrm{~kg} /$ dia para maior ganho de peso $(1,43 \mathrm{~kg} /$ animal/dia) e menor custo de produção (US\$ 0,78/kg de PV) sem comprometer a digestibilidade aparente total da maioria dos nutrientes.

\section{Literatura Citada}

ANUALPEC 2005. Anuário da Pecuária Brasileira. São Paulo: FNP Consultoria \& Comercio, 2005. 340p.

BM\&F. Bolsa de Mercadorias \& Futuros. Disponível em: <http:/ /www.bmf.com.br> Acesso em: 15/09/2005.

CARDOSO, R.C.; VALADARES FILHO, S.C.; COELHO DA SILVA, J.F. et al. Consumo e digestibilidades aparentes totais e parciais de rações contendo diferentes níveis de concentrado, em novilhos F1 Limousin x Nelore. Revista Brasileira de Zootecnia, v.29, n.6, p.1832-1843, 2000.

CARVALHO, A.U.; VALADARES FILHO, S.C.; COELHO DA SILVA, J.F. et al. Níveis de concentrado em dietas de zebuínos.
1. Consumo e digestibilidade aparente. Revista Brasileira de Zootecnia, v.26, n.5, p.986-995, 1997.

CAVALCANTE, M.A.B.; PEREIRA, O.G.; VALADARES FILHO, S.C. et al. Níveis de proteína bruta em dietas para bovinos de corte: consumo, digestibilidade total e desempenho produtivo. Revista Brasileira de Zootecnia, v.34, n.3, p.711-719, 2005.

CAVALCANTI, M.R. [2004] Acesso a mercados internacionais: a sanidade é o primeiro passo. Disponível em: <www.nelore.org.br.> Acesso em: 17/01/2004.

COELHO DA SILVA, J.F.; LEÃO, M.I. Fundamentos de nutrição de ruminantes. Piracicaba: Livroceres, 1979. 380p.

DIAS, H.L.C.; VALADARES FILHO, S.C.; COELHO DA SILVA, J.F. et al. Consumo e digestões totais e parciais em novilhos $F_{1}$ Limousin $\mathrm{x}$ Nelore alimentados com dietas contendo cinco níveis de concentrado. Revista Brasileira de Zootecnia, v.29, n.2, p.545-554, 2000.

FERREIRA, M.A.; VALADARES FILHO, S.C.; SILVA, J.F.C. et al. Consumo, conversão alimentar, ganho de peso e características de carcaça de bovinos $\mathrm{F}_{1}$ Simental x Nelore. Revista Brasileira de Zootecnia, v.28, n.2, p.343-351, 1999.

HALL, M.B. Calculation of non-structural carbohydrate content of feeds that contain non-protein nitrogen Gainesville: University of Florida, 2000. p.A-25 (Bulletin 339).

HADDAD, P.M. Uréia em suplementos alimentares. In: SIMPÓSIO SOBRE NUTIÇÃO DE BOVINOS - URÉIA PARA RUMINANTES, 2., 1984, Piracicaba. Anais... Piracicaba: Fundação de Estudos Agrários Luiz de Queiroz, 1984. p.119-141.

HOFFMAN, P.C.; ESSE, N.M.; BAUMAN, L.M. et al. Short communication: effect of dietary protein on growth and nitrogen balance of Holstein heifers. Journal of Dairy Science, v. 84 n.4, p.843-847, 2001.

ÍTAVO, L.C.V.; VALADARES FILHO, S.C.; SILVA, F.F. et al Consumo e digestibilidades aparentes totais e parciais de nutrientes em novilhos alimentados com dietas contendo vários níveis de concentrado. Revista Brasileira de Zootecnia, v.31, n.3, p.1543-1552, 2002a.

ÍTAVO, L.C.V.; VALADARES FILHO, S.C.; SILVA, F.F. et al. Níveis de concentrado e proteína bruta na dieta de bovinos Nelore nas fases de recria e terminação: consumo e digestibilidade. Revista Brasileira de Zootecnia, v.31, n.2, p.1033-1041, 2002b (supl.)

KÖPPEN, W. Climatologia. Buenos Aires: Panamericana, 1948. $478 \mathrm{p}$.

LADEIRA, M.M.; VALADARES FILHO, S.C.; SILVA, J.F.C. et al. Consumo e digestibilidades aparentes totais e parciais de dietas contendo diferentes níveis de concentrado, em novilhos Nelore. Revista Brasileira de Zootecnia, v.28, n.2, p.395-403, 1999.

McDONALD, D.R.; HENDERSON, A.R.; HERON, S.J.E. The biochemistry of silage. 2.ed. Aberystwyth: Chalcombe Publications, 1991. 340p.

MAGALHÃES, K.A.; VALADARES FILHO, S.C.; VALADARES, R.F.D. et al. Produção de proteína microbiana, concentração plasmática de uréia e excreções de uréia em novilhos alimentados. com diferentes níveis de uréia ou de casca de algodão. Revista Brasileira de Zootecnia, v.34, n.4, p.1400-1407, 2005.

MERTENS, D.R. Regulation of forage intake. In: FAHEY JR., G.C. (Ed.) Forage quality, evaluation and utilization. Madison: American Society of Agronomy, 1994. p.450-493.

MORAES, S.A; PEREIRA, O.G.; GARCIA, R. et al. Consumo e digestibilidade aparente de nutrientes, em bovinos recebendo dietas contendo silagem de milho e concentrado em diferentes proporções. In: REUNIÃO ANUAL DA SOCIEDADE BRASILEIRA DE ZOOTECNIA, 39., 2002, Recife. Anais... Recife: Sociedade Brasileira de Zootecnia, 2002. (CD ROM).

NATIONAL RESEARCH COUNCIL - NRC. Nutrient requirements of beef cattle. 7.ed. Washington, D.C.: National Academic of Sciences, 1996. 242p.

NATIONAL RESEARCH COUNCIL - NRC. Nutrient requirements of dairy cattle. 7.ed. Washington, D.C.: National Academic of Sciences, 2001. 381p. 
PELL, A.N.; SCHOFIELD, P. Computerized monitoring of gas production to measure forage digestion in vitro. Journal of Dairy Science, v.76, n.10, p.1063-1073, 1993.

PEREIRA, D.H. Silagem de sorgo (Sorghum bicolor (L.) Moench) e concentrado, em diferentes proporções, na dieta de bovinos de corte. Viçosa, MG: Universidade Federal de Viçosa, 2004. 74p. Dissertação (Mestrado em Zootecnia) - Universidade Federal de Viçosa. 2004.

RENNÓ, L.N.; VALADARES FILHO, S.C.; VALADARES, R.F.D. et al. Níveis de proteína na ração de novilhos de quatro grupos genéticos: estimativa da produção de proteína microbiana por intermédio dos derivados de purinas na urina. In: REUNIÃO ANUAL DA SOCIEDADE BRASILEIRA DE ZOOTECNIA, 40., 2003, Santa Maria. Anais... Santa Maria: Sociedade Brasileira de Zootecnia, 2003. (CD-ROM).

SILVA, D.J.; QUEIROZ, A.C. Análises de alimentos (métodos químicos e biológicos). 3.ed. Viçosa, MG: Editora UFV, 2002. $235 \mathrm{p}$.

SILVA, B.C.; PEREIRA, O.G.; PEREIRA, D.H. et al. Consumo e digestibilidade aparente total dos nutrientes e ganho de peso de bovinos de corte alimentados com silagem de Brachiaria brizantha e concentrado em diferentes proporções. Revista Brasileira de Zootecnia, v.34, n.3, p.1060-1069, 2005.

SOUZA, V.G.; PEREIRA, O.G.; VALADARES FILHO, S.C. et al. Consumo e desempenho de bovinos de corte recebendo silagem de milho e concentrado em diferentes proporções. In: REUNIÃO ANUAL DA SOCIEDADE BRASILEIRA DE ZOOTECNIA, 39., 2002, Recife. Anais... Recife: Sociedade Brasileira de Zootecnia, 2002. (CD-ROM).
UNIVERSIDADE FEDERAL DE VIÇOSA - UFV.SAEG. Sistemas de análises estatísticas e genéticas. Versão 8.0. Viçosa, MG, 2001. 301p. (Manual do usuário).

VALADARES, R.F.D.; GONÇALVES, L.C.; RODRIGUEZ, N.M. et al. Níveis de proteína em dietas de bovinos. 1. Consumo e digestibilidades aparentes totais e parciais. Revista Brasileira de Zootecnia, v.26, n.6, p.1252-1258, 1997.

VALADARES FILHO, S.C.; VALADARES, R.F.D. Recentes avanços em proteína na nutrição de vacas leiteiras. In: SIMPÓSIO INTERNACIONAL DE BOVINOCULTURA DE LEITE, 2., 2001, Lavras. Anais... Lavras: Universidade Federal de Lavras, 2001. p.228-243.

VALADARES FILHO, S.C.; ROCHA JR., V.R.; CAPPELLE, E.R. Tabelas brasileiras de composição de alimentos para bovinos. CQBAL 2.0. Viçosa: MG: Universidade Federal de Viçosa/Suprema Gráfica Ltda, 2002. 297p.

Van SOEST, P.J. Nutritional ecology of the ruminants. 2.ed. Ithaca: Cornell University, 1994. 476p.

Recebido: 01/12/05

Aprovado: 11/07/06 